\title{
WEIGHTED LIPSCHITZ ESTIMATES FOR COMMUTATORS OF ONE-SIDED OPERATORS ON ONE-SIDED TRIEBEL-LIZORKIN SPACES
}

\author{
Zun Wei Fu, GuAng Lan Wang And Qing YAN Wu
}

\begin{abstract}
Using the extrapolation of one-sided weights, we establish the boundedness of commutators generated by weighted Lipschitz functions and one-sided singular integral operators from weighted Lebesgue spaces to weighted one-sided Triebel-Lizorkin spaces. The corresponding results for commutators of one-sided discrete square functions are also obtained.
\end{abstract}

Mathematics subject classification (2010): 42B20, 42B25.

Keywords and phrases: one-sided weight, weighted Lipschitz function, one-sided Triebel-Lizorkin space, one-sided singular integral, one-sided discrete square function.

\section{REFERENCES}

[1] H. Aimar, R. Crescimbeni, On one-sided BMO and Lipschitz functions, Ann. Sc. Norm. Super. Pisa Cl. Sci., 27 (1998) 437-456.

[2] H. Aimar, L. Forzani, F. J. Martín-Reyes, On weighted inequalities for singular integrals, Proc. Amer. Math. Soc., 125 (1997) 2057-2064.

[3] K. F. ANDERSEN, E. T. SAWYER, Weighted norm inequalities for the Riemann-Liouville and Weyl fractional integral operators, Trans. Amer. Math. Soc., 308 (1988) 547-558.

[4] Z. W. Fu, S. Z. Lu, One-sided Triebel-Lizorkin space and its applications (in Chinese), Sci. Sin. Math., 41 (2011) 43-52.

[5] Z. W. Fu, S. Z. Lu, S. SATo, S. G. Shi, On weighted weak type norm inequalities for one-sided oscillatory singular integrals, Studia Math., 207 (2011) 137-151.

[6] J. García-Cuerva, Weighted $H^{p}$ spaces, Dissert. Mathematicae 162, Warszana, 1979.

[7] B. HU, J. J. GU, Necessary and sufficient conditions for boundedness of some commutators with weighted Lipschitz functions, J. Math. Anal. Appl., 340 (2008) 598-605.

[8] R. Jones, R. Kaufman, J. M. Rosenblatt, M. Wierde, Oscillation in ergodic theory, Ergodic Theory Dynam. Systems, 18 (1998) 889-935.

[9] Y. LiN, Z. G. LiU, G. X. PAN, Weighted Lipschitz estimates for commutators of fractional integrals with homogeneous kernels, Taiwanese J. Math., 15 (2011) 2689-2700.

[10] M. LoRENTE, M. S. Riveros, Two weight norm inequalities for commutators of one-sided singular integrals and the one-sided discrete square function, J. Aust. Math. Soc., 79 (2005) 7794.

[11] M. Lorente, M. S. Riveros, Weights for commutators of the one-sided discrete square function, the Weyl fractional integral and other one-sided operators, Proc. Roy. Soc. Edinburgh Sect. A, 135 (2005) 845-862.

[12] M. LoRENTE, M. S. Riveros, Two extrapolation theorems for related weights and applications, Math. Inequal. Appl., 10 (2007) 643-660.

[13] R. A. MACÍAs, M. S. Riveros, One-sided extrapolation at infinity and singular integrals, Proc. Roy. Soc. Edinburgh Sect. A, 130 (2000) 1081-1102.

[14] F. J. Martín-Reyes, P. Ortega Salvador, A. De la Torre, Weighted inequalities for onesided maximal functions, Trans. Amer. Math. Soc., 319 (1990) 517-534.

[15] F. J. Martín-Reyes, L. Pick, A. DE LA Torre, $A_{\infty}^{+}$condition, Canad. J. Math., 45 (1993) 12311244.

[16] F. J. Martín-Reyes, A. De La TorRe, Two weight norm inequalities for fractional one-sided maximal operators, Proc. Amer. Math. Soc., 117 (1993) 483-489. 
[17] F. J. Martín-Reyes, A. DE LA Torre, One-sided BMO spaces, J. London Math. Soc., 49 (1994) $529-542$.

[18] M. PALuSZyŃski, Characterization of the Besov spaces via the commutator operator of Coifman, Rochberg and Weiss, Indiana Univ. Math. J., 44 (1995) 1-17.

[19] J. PeEtre, On the theory of $\mathscr{L}_{p, \lambda}$ spaces, J. Funct. Anal., 4 (1969) 71-87.

[20] C. PÉREZ, Sharp estimates for commutators of singular integrals via iterations of the HardyLittlewood maximal function, J. Fourier Anal. Appl., 3 (1997) 743-756.

[21] L. DE Ros A, C. Segovia, Equivalence of norms in one-sided $H^{p}$ spaces, Collect. Math., 53 (2002) $1-20$.

[22] E. SAWYER, Weighted inequalities for the one-sided Hardy-Littlewood maximal functions, Trans. Amer. Math. Soc., 297 (1986) 53-61.

[23] C. SEgovia, J. L. TORREA, Weighted inequalities for commutators of fractional and singular integrals, Publ. Mat., 35 (1991) 209-235.

[24] A. Torchinsky, Real-variable methods in harmonic analysis, Academic Press, 1986.

[25] A. DE la Torre, J. L. Torrea, One-sided discrete square function, Studia Math., 156 (2003) 243 260.

[26] W. Yuan, W. Sickel, D. C. Yang, Morrey and Campanato Meet Besov, Lizorkin and Triebel, Lecture Notes in Mathematics 2005, Springer-Verlag, Berlin, 2010. 